\title{
Esophageal Gastrointestinal Stromal Tumor
}

National Cancer Institute

\section{Source}

National Cancer Institute. Esophageal Gastrointestinal Stromal Tumor. NCI Thesaurus.

Code C27430.

A gastrointestinal stromal tumor that arises from the esophagus. The majority are spindle cell tumors that exhibit high mitotic activity and affect the distal esophagus. 